\title{
Gerenciamento de Resíduos Sólidos e a Aplicação da Logística Reversa no Segmento da Construção Civil
}

\author{
João Paulo Cavalcante Matos ${ }^{\text {; }}$ Tharsis Cidália de Sá Barreto Diaz de Alencar ${ }^{2}$
}

\begin{abstract}
Resumo: A Construção Civil representa uma das mais importantes atividades para o desenvolvimento e fomento econômico de um país. Porém, este é um dos setores que mais impacta e agride ao meio ambiente, isto, quer seja pela grande exploração de recursos naturais, pelas mudanças das paisagens ou mesmo pela produção de resíduos oriundos dos canteiros de obras. Este último aspecto, constituirá a problemática abordada ao longo deste estudo. Nessa perspectiva, o artigo ora exposto tem por objetivo geral investigar a aplicação da logística reversa no segmento da construção civil, com ênfase nas alternativas adotadas para a segregação, coleta e disposição destes materiais. No que tange a metodologia, o estudo em questão utilizou a abordagem descritiva, de cunho qualitativo, sendo esta uma pesquisa bibliográfica, a qual foi desenvolvida com base em livros, artigos, dentre outras publicações. Observou-se que as operações desempenhadas no âmbito da construção civil geram, predominantemente, o montante da parcela de resíduos sólidos urbanos encontrados nos centros urbanos. Constatou-se que a gestão de resíduos provenientes da construção civil torna-se uma ferramenta de suma relevância, haja vista estabelecer diretrizes para a disposição dos resíduos em locais apropriados, emergindo como um instrumento efetivo para minimizar os impactos sofridos pela natureza, podendo promover uma redução substancial no consumo de recursos naturais não renováveis; além de reduzir áreas destinadas a aterro, isto pela minoração da massa de resíduos para reuso e reciclagem; bem como auxilia a atenuar os índices de poluição; dentre outros benefícios.
\end{abstract}

Palavras-chave: Resíduos Sólidos. Gerenciamento. Logística Reversa. Construção Civil.

\section{Solid Waste Management and the Application of Reverse Logistics in the Construction Segment}

\begin{abstract}
Civil Construction represents one of the most important activities for the development and economic development of a country. However, this is one of the sectors that most impacts and harms the environment, whether due to the great exploitation of natural resources, changes in landscapes or even the production of waste from construction sites. This last aspect will be the problem addressed throughout this study. In this perspective, the present article aims to investigate the application of reverse logistics in the civil construction segment, with emphasis on the alternatives adopted for the segregation, collection and disposal of these materials. Regarding the methodology, the study in question used the descriptive approach, of a qualitative nature, being a bibliographical research, which was developed based on books, articles, among other publications. It was observed that the operations carried out in the field of civil construction generate, predominantly, the amount of urban solid waste found in urban centers. It was verified that the management of waste from civil construction becomes a tool of great relevance, with a view to establishing guidelines for the disposal of waste in appropriate places, emerging as an effective instrument to minimize the impacts suffered by nature, being able to promote a substantial reduction in the consumption of non-renewable natural resources; in addition to reducing landfill sites, by reducing the mass of waste for reuse and recycling; as well as helping to reduce pollution rates; among other benefits.
\end{abstract}

Keywords: Solid Waste. Sustainability. Waste management. Logistics. Construction. Introdução

\footnotetext{
${ }^{1}$ Bacharel em Administração pela Faculdade Santa Maria - FSM, 2014. jpcm2010@gmail.com

${ }^{2}$ Professora Orientadora; Mestre em Engenharia de Produção pela Universidade Federal da Paraíba - UFPB. 
O exercício da responsabilidade pelos agentes envolvidos na geração, destinação, fiscalização e controle sobre os geradores e transportadores de resíduos, relaciona-se diretamente à capacidade e viabilidade no tocante a triagem de materiais, a qual é plenamente possível, desde que haja a devida classificação técnica, almejando a identificação e discriminação destes insumos, visando à reutilização dos agregados reciclados pelo setor da construção civil.

No contexto da responsabilidade ambiental, a preocupação com a sustentabilidade e com o meio ambiente se intensificou durante o fim do século passado, no qual as políticas públicas ambientais estavam restritas ao campo da saúde com foco no controle de doenças.

$\mathrm{Na}$ década de 1980 foram estabelecidos pelos países desenvolvidos sistemas de Gerenciamento de Resíduos resultantes dos mais diversos ramos, em decorrência da preocupação com os riscos que determinados materiais poderiam causar ao homem e a natureza (CALDERONI, 2015).

O gerenciamento é uma compilação de ações de cunho normativo-regulamentadoras, funcionais, financeiras, dentre outras, as quais envolvem o planejamento elaborado tendo por fulcro parâmetros sanitários, socioambientais, políticos, educacionais, culturais e econômicos.

Os aspectos mencionados são considerados essenciais para a geração, manejo, tratamento e disposição final dos resíduos sólidos, considerando que toda atividade humana resulta na geração de resíduos (LIMA; LIMA, 2012). O gerenciamento de resíduos surge como uma ferramenta efetiva para diminuir os impactos suportados pela natureza. Nesse panorama, aderir ao planejamento no campo da construção civil é sinônimo de economia de recursos, o que pode, de fato, minimizar os efeitos prejudiciais decorrentes da geração do grande volume de resíduos.

Sabe-se que a escassez de recursos naturais tem levado à busca por soluções que tragam o desenvolvimento econômico juntamente com o crescimento sustentável. A problemática advinda da geração de resíduos depositados de forma irregular em aterros ilegais, terrenos baldios, acostamentos das estradas e rodovias - a exemplo de contaminações do solo, do ar e da água, inundações, proliferação de vetores de doenças, dentre outros - requer uma maior atenção por parte dos agentes públicos e privados, uma vez que sua resolução é de interesse coletivo, almejando a proteção do meio ambiente.

Nesse cenário, medidas vem sendo implantadas com a finalidade de converter essa realidade, como exemplo, menciona-se a resolução n ${ }^{\circ}$. 307/02 do Conselho Nacional do Meio Ambiente - CONAMA. Este documento oficial apresenta orientações, estipula as diretrizes, 
além de definir critérios e procedimentos voltados a Gestão dos Resíduos da Construção Civil, firmando a responsabilidade compartilhada entre os geradores de resíduos, transportadores e municípios.

$\mathrm{Na}$ esfera da construção civil, a diversidade de materiais utilizados é vasta, há desde materiais combustíveis e provindos de petróleo; agregados como brita e areia, aglomerantes, a exemplo do cimento, cal, gesso e argamassas, obtidos através de procedimentos envolvendo extração mineral; bem como gêneros da manufatura, a exemplo de blocos, telhas, tubos, como PVC, cobre, aço, cerâmicas de revestimento, fios, dentre outros (LIMA; LIMA, 2012).

A busca pela sustentabilidade ambiental através do gerenciamento de resíduos sólidos se norteia com base em metodologias e processos integrados que tem por meta viabilizar a redução dos resíduos gerados (CALDERONI, 2015). Esta redução ocorre com a instituição de programas que permitem também a reutilização desse material.

Nesse sentido, a reciclagem é primordial, uma vez que os materiais poderão ser empregados como matéria-prima para a indústria, sendo reaproveitados e realocados em outras atividades, refletindo na geração de renda e fomento a economia (BÉRRIOS, 2009).

Ressalta-se que a Constituição Federal de 1988 assegura a proteção ao meio ambiente equilibrado, uma vez que seu artigo 225 estabelece que todos possuem direito a usufruir de um ao meio ambiente equilibrado, aspecto essencial à sadia qualidade de vida, impondo-se ao Poder Público e à coletividade o dever de defesa e preservação. Em tal perspectiva, a legislação ambiental referente às atividades de construção se consolidou ainda mais com o advento da já mencionada resolução CONAMA nº. 307, de 05 de julho de 2002.

O trabalho em questão enfoca a temática da logística reversa na construção civil, com destaque às alternativas aplicadas para a segregação, coleta e disposição destes materiais. A escolha do assunto deu-se pelo fato de que a Construção Civil é indubitavelmente um dos segmentos responsáveis pelo desenvolvimento socioeconômico do país, entretanto, esse ramo gera grandes impactos ambientais os quais se relacionam a exploração de recursos naturais, mudanças na paisagem e formação de resquícios e sobras. Neste ponto, salienta-se a relevância de tal estudo, uma vez que se propõe este a contribuir para a ampliação dos conhecimentos acerca do manejo dos resíduos provenientes da construção civil.

O presente estudo tem por objetivo geral investigar a aplicação da logística reversa no segmento da construção civil, apresentando alternativas para a segregação, coleta e disposição destes materiais. No que tange a metodologia, o estudo em questão utilizou a abordagem descritiva, de cunho qualitativo, consistindo em uma revisão sistemática. 
Sustentabilidade é um termo adotado para conceituar ações e atividades humanas que almejam suprir as demandas atuais dos indivíduos, sem comprometer o futuro das próximas gerações (VEIGA, 2015). Com efeito, a sustentabilidade remete a um ideal que se caracteriza principalmente pela constante busca de desenvolvimento econômico concomitante à preservação do ecossistema, isto, por meio da aquisição de medidas e implementação de ações para os mais variados setores das atividades humanas. Pode-se mencionar como exemplo de ações sustentáveis, a promoção da gestão sustentável nas organizações voltada a reduzir o desperdício de matéria-prima.

Para Manzini e Vezzoli (2015) a sustentabilidade ambiental condiz com a atuação do ser humano no sentido de não ter influência, nem tampouco interferir nos ciclos naturais do planeta, a fim de não diminuir o capital natural, a exemplo da fauna, flora, aquíferos, dentre outros, que serão transmitidos às gerações futuras.

Ou seja, os recursos naturais existentes atualmente devem ser preservados para que mais tarde haja condições de vida com qualidade na Terra, assim, o homem não deve degradar o ambiente, tendo em vista que depende dele para viver. Desse modo, é necessário que se estabeleça uma relação de desenvolvimento humano que relacione de forma harmoniosa crescimento econômico e desenvolvimento sustentável (VEIGA, 2015).

De acordo com Cavalcanti (1998) sustentabilidade significa a expectativa de atingir de modo contínuo condições iguais ou melhores de vida para uma coletividade de pessoas e seus sucessores em determinado biossistema. Em seu turno, sustentabilidade, de acordo com Sachs (1991 apud CAVALCANTI, 1998) constitui-se numa ideia dinâmica, que remete a reflexão em torno de soluções acerca das demandas crescentes das populações, isto, tanto no contexto nacional, quanto internacional.

De acordo com Chambers e Conway (1992 apud CAVALCANTI, 1998) para ser integral, a sustentabilidade ambiental se complementada pela sustentabilidade social. Os referidos autores assinalam que Sustentabilidade social diz respeito a dignidade humana e a qualidade de vida dos habitantes de um dado local..

Manzini e Vezzoli (2015) esclarecem que a sustentabilidade é um processo que requer um ajuste social e econômico com métodos e técnicas, para que a natureza atenda às necessidades básicas da comunidade. Através do que foi exposto nos parágrafos anteriores, pode-se considerar que a sustentabilidade ambiental desenvolve-se por meio de comportamentos éticos, nos seus aspectos culturais, mantendo uma preocupação na conservação e preservação da vida e do meio ambiente. 
Registra-se que foi com o advento da Constituição Federal de 1988, que se teve um marco legal responsável por dar um passo decisivo à formulação da política ambiental brasileira, tendo inclusive a Carta Cidadã dedicado um capítulo especialmente ao meio ambiente, explicitando que cabe ao governo e a sociedade a responsabilidade pela preservação, proteção e conservação da natureza.

Em conclusão, Cavalcanti (2001) destaca que a sustentabilidade ambiental caracterizase como sendo um conjunto de variáveis bastante importantes quando se almeja, por exemplo, analisar o comportamento das empresas, na medida em que permite constatar a presença e/ou ausência dessas práticas ambientais internamente.

Uma vez feitas tais considerações pertinentes à sustentabilidade ambiental de forma abrangente, com base na literatura mais abalizada, procede-se, na próxima seção do estudo, ao enfoque da responsabilidade social especificamente no setor da construção civil.

\section{Responsabilidade Social Setor da Construção Civil}

No setor da construção civil, várias atitudes podem ser colocadas em prática quando o tema é responsabilidade social e/ou desenvolvimento sustentável. Uma delas é a reciclagem de materiais pelo setor da construção civil, auxiliando na redução de custos e consequentemente amenizando o impacto ambiental ocasionado (PINTO, 2015).

Com o crescimento no setor das construções, automaticamente a quantidade de resíduos aumenta, demandando um manejo adequado perante o meio ambiente, criando alternativas para reduzir, reutilizar e reciclar estes resíduos. A reciclagem destes resíduos se tornou muito importante, pois a economia de matéria-prima compõe o principal fator de economia, seguida da economia de energia elétrica (CALDERONI, 2015).

Segundo Tachizawa e Garrett (2010) o contexto econômico do século XXI se caracteriza por uma rígida postura dos clientes voltada à expectativa de interagir com organizações que sejam éticas, tenham boa imagem institucional no mercado e atuem de forma responsável.

Já Aléssio (2013) considera que a responsabilidade social se concretiza por meio da atuação social-institucional, perpassando por todos os níveis da empresa, desde a elaboração da estratégia até a execução, buscando atribuir à organização uma característica altruísta e humanitarista. Adotando esta perspectiva, a organização estará, de fato, contribuindo para a sociedade, desempenhando uma substancial função social. 
Nesse prisma, a responsabilidade social se refere a um posicionamento estratégico que a organização se incumbe perante diversas questões que perpassam valores éticos, seja na relação com seu capital humano, seja na negociação com fornecedores, no respeito aos clientes e/ou consumidores, bem como a comunidade em que está inserida, além das práticas adotadas em relação ao meio-ambiente (ALÉSSIO, 2013).

Oliveira (2012) avalia que no Brasil, a aplicação em investimentos sociais e ambientais é tida como recente, em que pese existir um mercado consumidor consciente, exigente e mesmo ético em ascensão. Em tal cenário, tendo em vista o efeito globalizante, não se pode aceitar que o país fique a margem das novas perspectivas que pontuam cada vez mais a necessidade de defender e construir a cidadania primando pela valorização ao meio ambiente sadio.

Para D’Ambrósio (2010) a responsabilidade social tem foco na decisão de participar de forma mais intensa das ações comunitárias na região em que está inserido e minorar possíveis danos ambientais decorrentes do tipo de atividade que exerce. Sob outro ponto de vista, Daft (2015) a define como a responsabilidade ou encargo que tem a direção da empresa em primar por soluções e ações que contribuam para o bem-estar da sociedade e da própria organização.

A responsabilidade social e a sustentabilidade estão intrinsecamente relacionadas, tendo em vista que para alcançar a sustentabilidade faz-se necessário que a organização passe a aderir ao conceito de responsabilidade social. A responsabilidade social reflete a adesão continua e em caráter permanente dos gestores de diversos setores da economia em se engajarem num comportamento balizado na ética, melhorando a qualidade de vida de seus empregados e de suas respectivas famílias, bem como da comunidade local e da sociedade em geral.

\section{Resíduos Sólidos X Meio Ambiente}

No cenário mundial os problemas relacionados à poluição e à degradação ambiental crescem significativamente. A utilização dos recursos naturais de modo sustentável tem sido uma das maiores preocupações do homem. A poluição ambiental, apesar da existência de vários órgãos envolvidos com a conservação do meio ambiente, cresce de forma descontrolada e acaba afetando não só os ecossistemas como também a sociedade em si (CUNHA, 2011). Neste contexto, são abordados os Resíduos Sólidos provenientes de ambientes, salientando a importância do seu gerenciamento, almejando apontar meios que auxiliem a diminuir os impactos destes materiais sobre o meio ambiente. 
A diversidade e complexidade encontradas no ambiente constituem grandes desafios para o século XXI, essencialmente devido à grande quantidade de resíduos que são produzidos. No Brasil se produz em um único dia aproximadamente 250 mil toneladas de lixo, a cidade de São Paulo é a maior produtora de resíduos do país, com cerca de 19 mil toneladas diárias (ABRELPE, 2015).

Com isto, considera-se que a produção de resíduos e seu consequente depósito no ambiente é, contemporaneamente, um tema bastante debatido nos mais diversos meios de comunicação. Neste ponto, salienta-se que o atual modelo de desenvolvimento tecnológico e econômico predispõe a um consumismo ilimitado, tanto em países desenvolvidos, como em países pobres, como consequência disto, verifica-se a geração de resíduos como plásticos, papéis, lixos orgânicos, metais, resíduos do serviço de saúde e resíduos industriais. Porém, "o problema mais grave não está situado na geração de resíduos, e sim, no descarte e tratamento dos mesmos, principalmente nos países em que não há investimento em tecnologia para o gerenciamento de resíduos" (PESSOA, 2008, p. 78).

No país, a Constituição de 1988, artigo 24, XII, estabelece que a limpeza pública, coleta, transporte e disposição de resíduos sólidos são de responsabilidade da União, dos Estados e do Distrito Federal, cabendo as estes legislarem sobre a defesa e a proteção à saúde, no entanto, os municípios possuem autonomia para criar suas próprias leis, e é ele quem deve se encarregar pela coleta e fins dos resíduos sólidos.

Segundo Bérrios (2009) lixo é definido com o produto que se encontra na parte final de um processo, ou seja, tudo que foi desprezado ao longo da fabricação, ou que, por algum motivo, não pode ser reutilizado e reciclado. Na língua portuguesa, o termo resíduo sólido vem, gradativamente, substituindo a palavra lixo, isto se configura em uma medida a fim de atribuir uma conotação diferente aos rejeitos e sobras. Em seu turno, Teixeira e Bidone (2009) afirmam que para definir lixo, ou resíduos sólidos, são encontradas dificuldades, haja vista que existem diversas formas e pontos de vistas para fazê-lo, e em geral, são definidos com a preferência de cada autor.

A Associação Brasileira de Normas Técnicas - ABNT (2004) considera os resíduos sólidos relacionando-os com as atividades de origem. Desse modo, os resíduos nos estados sólidos e semissólidos são resultantes de atividades industriais, domésticas, hospitalares, comerciais, agrícolas, de serviços e de varredura.

Estão inseridos em tal classificação os lodos oriundos de sistemas de tratamento de água, ou seja, os resultantes de equipamentos e instalações de controle da poluição, bem como alguns 
líquidos cujas peculiaridades os tornam inviáveis de serem lançados na rede pública de esgotos, ou exijam para isso determinada solução técnica.

A Organização Mundial de Saúde - OMS, segundo Demajorovic (1995 apud CUNHA, 2011) configura os resíduos como sendo tipos de materiais que o proprietário não mais deseja, em certo momento e em determinado local, e que não tem valor de mercado. Em função do valor agregado de cada material, resíduos sólidos são recursos que estão no lugar e na hora errada (TEIXEIRA; BIDONE, 2009).

Em complemento, Demajorovic (1995 apud CUNHA, 2011) infere que a substituição do termo "lixo" por "resíduos sólidos" implica numa compreensão de que alguns subprodutos possuem valor econômico por possibilitarem reaproveitamento no processo produtivo.

No Novo Dicionário Básico da Língua Portuguesa o lixo é o que se varre das residências, dos jardins, dos quintais, da rua, enfim. Tudo o que não tem serventia; sujeira, inutilizadas (FERREIRA, 2017), significando todo e qualquer resíduo da atividade humana.

Vale reiterar que os resíduos sólidos apresentam grande multiplicidade, se originando das mais distintas formas de atuações humanas. Constituem essa massa de materiais reunidos, julgada sem utilidade e posta fora, bagaços de frutas, cascas de legumes e sobras de alimentos em geral, além de embalagens plásticas e de metais, vidros, papéis, materiais cerâmicos, ossos, couro, terra, pedra, material séptico ou contaminado, animais mortos, dentre outros (TEIXEIRA; BIDONE, 2009).

A variedade de resíduos sólidos existentes é enorme, entretanto, vale salientar que é possível reduzir significativamente o volume de lixo por meio de um consumo e uso de materiais e produtos de modo racional, isso fica evidenciado em medidas com foco na reutilização e reciclagem.

As complicações decorrentes do manejo equivocado dos resíduos sólidos são bastante sérias, dentre elas: contaminação por bactérias, vírus, fundos, poluição do solo, do ar, da água, entupimento das redes de drenagem, enchentes, degradação ambiental, além de demais tão graves quanto as mencionadas.

A seguir, descrevem-se critérios básicos que foram estabelecidos pela Resolução $n$. 001/1986-CONAMA, em que se fixam definições, diretrizes genéricas de ações administrativas, bem como se formula a conceituação de impacto ambiental, mencionados no art. $1^{\circ}$ da referida Resolução:

Impacto ambiental é qualquer alteração das propriedades físicas, químicas e biológicas do meio ambiente, causada por qualquer forma de matéria ou energia resultante de atividades humanas que, direta ou indiretamente, afetem: a saúde, 
segurança e o bem-estar da população; as atividades sociais e econômicas; a biota; as condições estéticas e sanitárias e o meio ambiente e a qualidade dos recursos ambientais (CONAMA, 1986).

Grande parcela dos materiais gerados não possui um desígnio sanitário que seja legalmente e ambientalmente adequado. Em que pese uma significativa evolução e maior conscientização por parte do governo, dos gestores e da população, ocorridas nas últimas décadas, ainda é bastante frequente a destinação irregular de resíduos.

Os aterros clandestinos são frequentemente encontrados em municípios brasileiros, o chorume, líquido poluente de coloração escura e odor nauseante, originado da decomposição de resíduos, é um dos maiores vetores de doenças, por se infiltrar no solo e contaminar as águas subterrâneas (MUÑOZ, 2012).

Há também o perigo existente devido a emissão de gases e demais poluentes atmosféricos, relativos ao processo de combustão do lixo feita ao ar livre, medida comum realizada em vários municípios. Os impactos provenientes de toda essa devastação ambiental se ampliam para além dos locais de disposição final dos resíduos, afetando a coletividade como um todo, e em maior grau, os moradores das adjacências dos aterros (GOUVEIA, 2012).

O capítulo seguinte aborda o gerenciamento de resíduos sólidos na construção civil, trazendo os principais aspectos relacionados à reciclagem, reuso e segregação com fundamento na Resolução Conama nº 307 de 2002, enfocada com maior detalhamento na seção seguinte.

\section{Gerenciamento de Resíduos da Construção Civil}

A Resolução CONAMA nº. 307/02, com o objetivo de minimizar os impactos ambientais provocados pelos resíduos da construção civil, estabeleceu diretrizes, critérios e procedimentos para serem implantados durante a execução das obras. Essas ações podem e devem ser empregadas em todo e qualquer tipo de construção que provoque a geração de resíduos (CONAMA, 2002).

A necessidade de se implementar o gerenciamento dos resíduos na construção civil está diretamente relacionada ao volumoso desperdício de materiais, especialmente nas etapas que integram o processo de construção. A minimização da geração é um dos pontos cruciais para que o método de gerenciamento de resíduos seja eficaz (JOHN, 2010). Dessa forma, durante tal capítulo procurou-se sugerir técnicas que venham contribuir com a gestão dos resíduos provenientes do canteiro de obras. 
Cabe frisar que dentre os aspectos que corroboram para a formação dos Resíduos da Construção Civil - RCC, podem ser apontados os problemas inerentes ao projeto inicial da obra, isto, pela ausência de especificações técnicas, carência na precisão nos memoriais descritivos, má qualidade dos materiais adquiridos, mão-de-obra sem qualificação, erro no manejo, transporte e armazenamento dos materiais, ausência de instrumentos de controle ao longo da execução da obra, equívocos na seleção da melhor técnica para construção e demolição, falta de reutilização e reciclagem no canteiro, dentre outros (LIMA; LIMA, 2012).

Ao adotar medidas almejando gerir os RCC, as construtoras podem agregar inúmeras vantagens, como por exemplo: estar em consonância com a legislação local e garantir o alcance de certificação em programas de sustentabilidade; operacionalizar a limpeza do canteiro, ação que contribui para organização da obra, redução dos riscos de acidentes laborais, restrição racional ao uso de recursos naturais e, consequentemente a redução de resíduos (JOHN, 2010).

Conforme o autor supracitado, os resíduos de construção civil são originados em sua maior parte por demolições, obras renovadas, edificações novas, bem como em decorrência do desperdício de materiais com vistas às características manuais da construção. No Brasil, em torno $98 \%$ das obras recorrem ao uso de métodos tradicionais (JOHN, 2010). A Resolução CONAMA no 307/02 define RCC como:

\footnotetext{
Materiais provenientes de construções, reformas, reparos e demolições de obras de construção civil, e os resultantes da preparação e da escavação de terrenos, tais como: tijolos, blocos cerâmicos, concreto em geral, solos, rochas, metais, resinas, colas, tintas, madeiras e compensados, forros, argamassa, gesso, telhas, pavimento asfáltico, vidros, plásticos, tubulações, fiação elétrica etc., comumente chamados de entulhos de obras, caliça ou metralha (CONAMA, 2002).
}

Este documento conceitua gerenciamento de resíduos como uma sistemática de gestão cuja finalidade é de diminuir, reutilizar ou reciclar resíduos, abrangendo planejamento, atribuição de responsabilidades, adesão a práticas, observância a procedimentos e uso racional de recursos, com o intuito de desenvolver e implementar medidas necessárias ao cumprimento das etapas estipuladas em programas e planos (CONAMA, 2002).

De acordo com Monteiro et. al. (2001 apud MARIANO, 2012), a produção de RCC no país gira em torno de $300 \mathrm{~kg} / \mathrm{m}^{2}$ a partir de novas construções. Por outro lado, em países desenvolvidos essa quantidade chega $100 \mathrm{~kg} / \mathrm{m}^{2}$. Em municípios com 500 mil ou mais habitantes os RCC representam cerca de $50 \%$ do peso dos resíduos sólidos urbanos coletados (MARIANO, 2012), 
O autor supramencionado esclarece que para mensurar a quantidade de resíduos gerados pelo setor de construção civil no Brasil, são utilizados dados em forma de estimativas e percentuais com base em áreas construídas, além disso, são levantados dados de quantificação de volumes junto a empresas coletoras.

As referidas formas de elaborar estimativas possibilitam uma quantificação de maior confiabilidade, podendo ser adotadas em todas as cidades com construções licenciadas cadastradas junto aos órgãos responsáveis (PINTO, 2015). O mesmo autor releva que a composição dos resíduos da construção civil gerados em um a canteiro de obras no Brasil é constituída, em sua maior parte por argamassa, concreto e blocos de concreto, bem como madeiras, plásticos, papel e papelão.

Em se tratando de outros países, a composição dos seus resíduos provenientes da construção civil varia muito muda, sendo estes compostos, além do concreto e blocos de concreto, por gesso e o EPS utilizado para isolamento, atingindo geração de $30,77 \mathrm{~kg} / \mathrm{m}^{2}$ (BOHNE; BERGSDAL; BRATTEBO, 2005 apud MARIANO, 2012). Segundo Kimbert (2002 apud ROCHA; JOHN, 2013) esta quantidade é de $25 \mathrm{~kg} / \mathrm{m}^{2}$ para novas construções e de 320 $\mathrm{kg} / \mathrm{m}^{2}$ quando são realizadas demolições.

No que diz respeito ao potencial de contaminação dos resíduos acima mencionados, este será determinado em conformidade com as normas da Associação Brasileira de Normas Técnicas NBR nº 10.004/04, nº. 10.005/04 e nº 10.006/04 (ABNT, 2004). Valendo ressaltar que o tratamento dispensado aos resíduos será definido por ações voltadas a diminuir a quantidade ou mesmo a potencialidade de poluição.

O entulho da construção civil é classificado como sendo de Classe II B - inerte (ABNT, 2004), estando seu tratamento condicionado à redução de seu volume. O tratamento mais propagado, além da diminuição, é a segregação, trituração e reutilização. Por sua vez, o modo mais conhecido e adotado de reuso está voltado à construção de rodovias, como base ou subbase e para preencher pontos não estruturais de edificações (MARIANO, 2012).

No "Guia Wambuco" (2002 apud ROCHA; JOHN, 2013) são apontadas tecnologias objetivando prevenir e minimizar a formação de refugos através da escolha do tipo de material utilizado na obra, como madeira, telhas, tinta branca de chumbo, tijolos, cerâmicas, entulhos, dentre outros. Ainda, citam-se os aspectos de resíduos no processo de restauro, conservação ou demolição de edificações antigas.

Outro exemplo, o "Guia de Boas Práticas", desenvolvido pela Universidade de Cardiff em 2003 (GREENWOOD, 2003 apud MARIANO, 2012), no Reino Unido, traz uma sistemática voltada para minimizar os resíduos, sendo esta formada por fases de não-geração, 
redução, reuso, reciclagem e disposição final. Esta sistemática pode ser inserida em qualquer plano de gerenciamento de resíduos.

O “Guia de Boas Práticas” comporta informações no tocante a conceituação de resíduos, tratando ainda de identificar possíveis causas da geração destes, a necessidade de diminui-los, além de apresentar importantes iniciativas de combate ao desperdício.

O planejamento elaborado para minimizar a produção de resíduos, baseia-se na análise do desperdício e nas oportunidades para que de fato seja alcançada a diminuição, execução, acompanhamento e ajustes do projeto, bem como no cumprimento às exigências legais, a exemplo da proteção ambiental, controle de ruídos, gestão da água, conservação, preservação, avaliação do impacto ambiental, sistema de gerência socioambiental, legislações dessa área, além dos estudos de caso (JOHN, 2010).

Em continuidade, ainda acerca do gerenciamento de resíduos, o relatório versando acerca das práticas de gerenciamento de RCC e de seus impactos econômicos, apresentado pelo grupo Symonds (1999 apud MARIANO, 2012), teve por intuito preconizar a gestão de resíduos, através hierarquia de redução, reuso, reciclagem e a disposição final.

Este relatório também apresenta considerações econômicas e administrativas para auxiliar na decisão pela reutilização ou reciclagem, além de orientador sobre boas práticas nos mais distintos lugares, destacar estimativas de produção de resíduos em diferentes países da União Europeia, frisando as práticas já implantadas que funcionaram no sentido de diminuir a geração de resíduos.

O documento constatou que para ser efetivada uma verdadeira mudança no gerenciamento de RCC, faz necessário da ênfase às ações envolvendo melhorias nos instrumentos de controle dos aterros para este tipo de resíduo; maior mensuração dos custos para a disposição final destes materiais; tratamento da fração inerte e volumosa dos resíduos antes do reuso ou reciclagem e; conscientização dos usuários no que tange a importância de aderir ao uso de produtos reciclados (MARIANO, 2012).

Portanto, observando que a geração de RCC não pode ser totalmente eliminada, a elaboração de um gerenciamento de resíduos é fundamental para que sejam adotadas e implementadas práticas voltadas para minimizar a formulação em grande volume destes resíduos, bem como evitar os desperdícios, tendo por fundamento o reaproveitando das partes recicláveis (JOHN, 2010).

No cenário contemporâneo, é primordial fomentar e incentivar a prática d de processos inovadores na construção civil. Nesse ponto, salienta-se que a reciclagem e o reuso de materiais emergem como solução para que os materiais não sejam integralmente dispensados. Vale frisar, 
que segundo a resolução 307/2002 - CONAMA, para realização da triagem, esta deve ser feita, de modo preferencial, nas áreas de destinação licenciadas para esse fim, observadas as classificações dos resíduos.

Os entulhos originados da construção civil possuem destinações diversas, aço, por exemplo, é bastante comercializado, as madeiras também são vendidas, mas quando isto não ocorre, elas são recolhidas como "entulho leve". Por sua vez, material pesado proveniente da obra, constitui-se predominantemente pelas de argamassa. Geralmente as demais sobras são elementos de vedação, como tijolos, blocos e materiais de revestimento (PINTO, 2015).

Nesse contexto, a reciclagem destes resíduos tem por fito transformar esses custos sociais em custos públicos ou privados, no qual toda cadeia envolvida irá interferir trazendo contribuições em forma de ações a fim de diminuir a geração dos resíduos de construção, uma vez que de forma direta ou indireta todos são responsáveis e estão envolvidos (PINTO, 2015).

Investir em práticas de reutilização, na coleta realizada de forma seletiva e na reciclagem dos entulhos, proporciona diversos benefícios às construtoras, desde a redução com os custos de matéria-prima, despesas com o transporte, taxas de despejo de materiais em aterro, dentre outros. Igualmente, implantar programas e planos visando reduzir perdas em todas as fases da construção contribuem diretamente para diminuir a geração do RCC (CARNEIRO et. al., 2011).

\section{Aplicação da Logística Reversa na Construção Civil}

De acordo com Pinto; Lima Júnior (2014) o setor da construção civil no século XXI vem passando por significativas mudanças, isto, devido principalmente, ao grande avanço tecnológico, o que refletiu em ganhos e benefícios no sentido de maior qualidade, aumento da produtividade, além da redução de custos e intensificação competitividade no mercado.

Aderir a práticas racionais e de otimização nesse ramo, almejando aprimorar técnicas, empregar mais equitativamente os materiais, viabiliza empreendimentos sustentáveis, elevando a competição entre as empresas do ramo na busca por novos clientes e por novas soluções (PINTO, 2015). Em divergência, Stachera (2008) afirma que embora haja uma preocupação ambiental, a indústria da construção civil no Brasil ainda está longe de desenvolver produtos ecologicamente corretos.

Avaliar minuciosamente as diferentes variáveis que compõe a logística nas obras da construção civil torna mais rápida a identificação dos problemas que podem ser encontrados nesse ramo, sendo bem mais concisa, objetiva e assertiva a seleção das técnicas a serem 
empregadas nesse setor da economia, a fim de efetivar processos reversos e a redução de custos (PINTO; LIMA JÚNIOR, 2014).

Contudo, Alt; Martins (2011) alertam que os métodos de análise e avaliação de uso sustentável dos materiais na construção civil, bem como do plano de logística, devem ser desenvolvidos para uso local, pois características regionais, como variações climáticas, nível de renda financeira, materiais de construção, técnicas locais e valores históricos regionais variam de acordo com cada região, alterando os sistemas de ponderação de avaliação.

Pinto; Lima Júnior (2014) avaliam que no campo da construção civil, a ampla gama de materiais utilizados nas edificações caracteriza esse setor, bem como as diferentes variações em seus processos e produtos. Devido a isso, se torna fundamental empregar técnicas gerenciais com enfoque nos aspectos de planejamento, controle, avaliação de performance e redução dos custos.

O ciclo planejamento-programação-execução-acompanhamento é um dos pontos cruciais que caracterizam esse setor, o qual tem por meta apresentar um resultado final satisfatório entre as diferentes atividades executadas, as quais interagem entre si, devendo estar plenamente compatibilizadas, buscando gerar produtos com alto desempenho, conforme Torgal; Jalali (2007).

Estimativas apontam que a construção civil é o setor responsável por até mais de $50 \%$ do uso de recursos naturais, isto varia, a depender do tipo de tecnologia a ser adotada na edificação. Assinala-se ainda que na construção de um edifício, o transporte, juntamente com a fabricação dos materiais abarca em torno de $80 \%$ da energia dispendida (PINTO; LIMA JÚNIOR, 2014).

A vasta gama de materiais utilizados e o considerável emprego de recursos naturais ratificam a relevância de serem reaproveitados todos os materiais nos canteiros de obras na construção civil. Nesse panorama, reciclar materiais de entulho se constitui em um instrumento para alcançar vantagens e aumentar a competitividade no setor da construção civil, conforme registram Pinto e Lima Júnior (2014).

Chaves; Martins (2005) salientam outro ponto que vem contribuindo para o constante crescimento da logística reversa no âmbito da construção civil. Segundo estes autores, o motivo dessa ascensão ocorre devido ao enorme potencial econômico que reveste o processo logístico reverso, o qual ainda não vem sendo devidamente explorado em toda sua amplitude no setor da construção.

Segundo Cardoso (1996 apud PINTO; LIMA JÚNIOR, 2014), a racionalização da produção pode ser compreendida como o conjunto de fontes e instrumentos gerenciais voltados 
à busca por maior eficiência, tento em vista as distintas variáveis existentes no mercado e a capacidade de analisar e operacionalizar os métodos de organização, gestão e a tomada de decisão.

Particularmente no setor da construção civil, o interesse na melhoria dos índices de competitividade ainda é relativamente incipiente, sendo esta uma busca de um grupo de grandes organizações, as quais ainda estão iniciando na implantação de ações as iniciativas como foco no gerenciamento de resíduos. Desta forma, faz-se necessária uma visão sistêmica das questões que afetam estes fluxos, devendo ser identificados os entraves a serem sanados para a viabilização de um sistema logístico voltado às obras civis (PINTO; LIMA JÚNIOR, 2014).

Lalt (2003 apud PINTO; LIMA JÚNIOR, 2014) acentua que os problemas observados na construção civil são relacionados aos fluxos físicos de materiais e aos fluxos de informações. Conforme este autor, a ausência de um planejamento minucioso do arranjo físico do canteiro de obras, visando estabelecer e definir os fluxos dos principais materiais e de informações, bem como a eliminação de fluxos dispensáveis, traz prejuízos significativos às empresas de construção, impactando em diversos aspectos, sejam financeiros, ou em relação ao desempenho da organização.

A implantação da logística reversa revela-se como uma oportunidade ímpar de se desenvolver e sistematizar os fluxos de resíduos, bens e produtos rejeitados. Nesse sentido, o reaproveitamento, dentro ou fora da cadeia de produção que o originou, contribuirá diretamente para a redução do uso de recursos naturais e dos impactos ambientais (PINTO; LIMA JÚNIOR, 2014).

Para Schenini et. al. (2004) a disponibilidade de locais e instalações para receber os materiais, proceder a triagem e processar os resíduos da construção civil, propicia aos municípios e suas comunidades adjacentes grande benefícios ambientais, econômicos e sociais, eliminando boa parte dos despejos feitos clandestinamente, melhorando a paisagem urbana, além de elevar a qualidade de vida dos moradores.

Ressalta-se que a logística reversa abarca, em seu significado mais amplo, todas as operações relativas ao reuso de produtos e materiais, englobando todas as atividades logísticas de coleta, desmonte e processamento de produtos e/ou materiais usados, almejando assegurar uma recuperação sustentável (LEITE, 2016). O autor supracitado esclarece que ainda que em termos práticos, a logística reversa tem como objetivo principal atenuar a poluição do meio ambiente e reduzir os desperdícios de matérias-primas, através de ações voltadas a reutilização e reciclagem. 


\section{Ações para minimização de resíduos na Construção Civil}

Baseando-se no estudo de Tozzi (2006), sugere-se como primeira ação no canteiro de obras a construção de locais próprios para realizar a coleta seletiva. Desta forma, os resíduos provenientes da construção ou demolição nas obras passarão serão classificados, para, posteriormente, serem dispostos na baia correspondente a sua classe, conforme definido pela Resolução CONAMA no 307/02 (TOZZI, 2006). De acordo com tal o art. 10 desta Resolução, os resíduos da construção civil deverão ser destinados das seguintes formas:

I - Classe A: deverão ser reutilizados ou reciclados na forma de agregados, ou encaminhados a áreas de aterro de resíduos da construção civil, sendo dispostos de modo a permitir a sua utilização ou reciclagem futura;

II - Classe B: deverão ser reutilizados, reciclados ou encaminhados a áreas de armazenamento temporário, sendo dispostos de modo a permitir a sua utilização ou reciclagem futura;

III - Classe C: deverão ser armazenados, transportados e destinados em conformidade com as normas técnicas especificas.

IV - Classe D: deverão ser armazenados, transportados, reutilizados e destinados em conformidade com as normas técnicas especificas.

A triagem dos resíduos também se constitui em uma etapa relevante no processo de definição das alternativas de reutilização, reciclagem e disposição final, tendo em vista que cada resíduo gerado apresenta uma característica particular o que, consequentemente, requer uma forma de disposição final específica. Além disso, a separação dos materiais contribui para a caracterização dos resíduos gerados (TOZZI, 2006).

John (2001) subdivide o processo de reciclagem dos resíduos sólidos em primária e secundária. A primária se realiza no mesmo processo que originou o material; é bastante aplicada na produção do aço e do vidro, embora nem sempre essa técnica seja economicamente viável, existindo a necessidade de um controle detalhado em relação a uniformidade das matérias-primas.

Por sua vez, a reciclagem secundária é conceituada como aquele na qual o resíduo é inserido em um processo produtivo distinto do que o originou, este tipo apresenta diversas possibilidades. John (2001) constata que a maior parcela dos materiais empregados na construção civil é composta de forma simples, tendo grande variabilidade, exigindo baixas resistências mecânicas, sendo, portanto, a reciclagem secundária o meio a ser mais explorado. 
Segundo Schenini et. al. (2004) são diversos os empregos possíveis para os materiais reciclados provenientes de canteiros de obras, sendo os principais: a) Utilização em pavimentação; b) Utilização como agregado para o concreto; c) Utilização como agregado para a confecção de argamassa; d) Outros usos, como o ascalhamento de estradas; preenchimento em construções; preenchimento de valas de instalações e reforço de aterros.

O planejamento do gerenciamento de resíduos, além de identificar, classificar e quantificar estes, visa ainda minimizar a geração em todas as fases da construção, buscando também maximizar o reaproveitamento e estabelecer uma destinação adequado para aqueles materiais que não tenham mais uso no canteiro da obra.

Nesse sentido, Xavier; Rocha (2001) afirma que uma alternativa eficiente para equacionar a reciclagem, é fazer uso de avaliações no próprio canteiro, como: verificar a parcela gerada de detritos; descrever de sua composição e seus elementos principais, identificar as áreas disponíveis para destinar os entulhos, e verificar as possibilidades de comercializar as sobras de madeira, metais, papel e plástico.

Proceder a identificação das características de cada uma das etapas do processo de construção civil é de fundamental relevância, pois assim, será possível adotar determinadas medidas objetivando reduzir o desperdício de materiais e, consequentemente, minimizar a geração de resíduos em várias atividades (TOZZI, 2006).

O reaproveitamento dos materiais abrange a análise dos resíduos dispostos, para que assim seja possível escolher dentre as melhores alternativas de para reaproveitá-los ou proceder a reciclagem dentro e fora do canteiro da obra, diminuindo a parcela para disposição final. Quantificar os resíduos e separá-los por classes, permitirá a caracterização do material desperdiçado na da obra (PINTO, 2015).

A Resolução CONAMA n. 307/02 preconiza ser de fundamental importância para a operacionalização da gestão sustentável dos RCC, o reaproveitamento de resíduos. Na fase de implantação no canteiro da obra, destaca-se a importância de ser avaliada a possibilidade de reaproveitar materiais gerados, a fim de evitar sua remoção e disposição final.

Tozzi (2006) avaliou em sua pesquisa que uma prática implementada no canteiro de obra, com o objetivo de minimizar a geração de resíduos, é aplicada durante o revestimento das paredes internas dos sobrados. Tendo em vista que nas obras, durante a execução dessa atividade, um volume significativo de resíduos originados de argamassa muitas vezes a caem no pavimento. Sendo assim, para reduzir a perda de material durante esta atividade, o autor supracitado recomenda que todo resíduo caído ao chão seja reunido e levado novamente à 
betoneira, para que seja feito o reaproveitamento. Assim, se reduz o volume de resíduos de argamassa gerado.

Ainda no que concerne ao reaproveitamento da Argamassa, Tozzi (2006, p. 69) acentua que "esta pode ser reutilizada no próprio canteiro da obra, em substituição ao agregado areia, na preparação do reboco utilizado no revestimento dos muros dos sobrados".

Tozzi (2006) afirma ainda que por não apresentar nenhuma função estrutural, a qualidade do reboco não é alterada em função da substituição da areia pelo resíduo da argamassa, que apresenta consistência muito parecida à da própria areia, conforme o autor supracitado.

É importante ressaltar que o reboco tradicional é preparado com cimento, cal e areia. Além de não alterar o funcionamento do revestimento, esta substituição contribuiu para economizar um dos recursos naturais mais utilizados na construção civil, a areia (PINTO, 2015).

De acordo com a Cartilha de Gerenciamento de Resíduos Sólidos para Construção Civil (2005), a aplicabilidade do planejamento de gerenciamento de resíduos no canteiro da obra envolve todos os pontos relativos à formação de RCC. Desta forma, são apresentadas alternativas de disposição final, em conformidade com a legislação federal, para os resíduos que não apresentam possibilidade de reaproveitamento. O Quadro 01 apresenta sugestões para destinação dos resíduos gerados na construção civil:

Quadro 01: Destinação dos Resíduos Gerados na Obra

\begin{tabular}{|c|c|l||}
\hline TIPO DO RESÍDUO & CLASSE & \multicolumn{1}{|c|}{ DESTINO } \\
\hline Argamassa & A & Reutilização no canteiro da obra \\
\hline Argamassa endurecida & A & $\begin{array}{l}\text { Aterro de resíduos da construção } \\
\text { civil }\end{array}$ \\
\hline Caliça & A & Reutilização no canteiro da obra \\
\hline Concreto & A & $\begin{array}{l}\text { Aterro de resíduos da construção } \\
\text { civil }\end{array}$ \\
\hline Gesso & C & $\begin{array}{l}\text { Devolução do resíduo a empresa de } \\
\text { origem }\end{array}$ \\
\hline Latas de tintas e solventes & D & $\begin{array}{l}\text { Aterro industrial para resíduos } \\
\text { perigosos }\end{array}$ \\
\hline Madeira & B & $\begin{array}{l}\text { Doação para reutilização fora do } \\
\text { canteiro da obra }\end{array}$ \\
\hline Papel / Papelão & B & $\begin{array}{l}\text { Venda para reciclagem fora do } \\
\text { canteiro da obra }\end{array}$ \\
\hline Tijolos & A & $\begin{array}{l}\text { Aterro de resíduos da construção } \\
\text { civil }\end{array}$ \\
\hline
\end{tabular}

Fonte: Tozzi (2006, p. 75). 
Pinto (2015) registra que medidas simples, voltadas à organização no canteiro, podem evitar diversos desperdícios no uso e na obtenção dos materiais. Em muitos canteiros de obras, os materiais ficam despejados ao chão, o que faz com que estes sejam descartados como resíduos inúteis. Esses insumos espalhados podem ser organizados, triados, classificados e divididos para que se torne possível transforma-los em resíduos de reuso.

Frisa-se que já existem inúmeras soluções para valorizar e dar uma função aos entulhos provenientes da construção civil. Como exemplo, máquinas portáteis podem ser adquiridas e utilizadas no canteiro, com a finalidade de triturar os entulhos selecionados, a fim de gerar agregados para serem empregados em concretos não estruturais (FERREIRA, 2012).

Outra medida é caminhar por toda área da obra, buscando olhar atentamente em busca de possíveis descartes de materiais, a exemplo de sacos de cimento e argamassa contendo restos dos produtos, além de tijolos quebrados, pedaços de conduítes para reutilização, dentre outros, sendo necessário recolher esses materiais para classificá-los e, em um segundo momento, disponibilizá-los para uso na própria obra até que estes findem por completo, o que gerará uma economia bastante significativa (PINTO, 2015).

Essa ação permitirá condensar a quantidade de resíduos produzidos e otimizar a realocação da mão-de-obra nas atividades diversas do canteiro de obras. Vale destacar que diminuir os materiais gerados impacta diretamente em uma redução nos custos relacionados ao transporte e na destinação final.

O desempenho conjunto das responsabilidades em torno dos resíduos pelos atores envolvidos na cadeia de geração, destinação, fiscalização dos geradores e transportadores, está condicionado ao processo de triagem o qual agrega valor a estes resíduos os quais, por sua vez, serão reutilizados e reciclados, isto, desde que haja especificação técnica para o uso de agregados reciclados na atividade da construção civil.

As normas técnicas que estabelecem as condições para utilização destes agregados são as seguintes: Agregados reciclados de resíduos sólidos da Construção Civil - Execução de camadas de pavimentação - Procedimentos - NBR 15115 de 2004; Agregados reciclados de resíduos sólidos da Construção Civil - Utilização em pavimentação e preparo de concreto sem função estrutural - Requisitos - NBR 15116 de 2004.

Lima e Lima (2012) aduzem que para o devido recolhimento e a transferência dos resíduos do canteiro de obras para outros lugares, se faz necessário o preenchimento de uma guia onde estarão discriminados os dados do gerador, tipo e quantidade de resíduos, dados do transportador e dados do local para onde serão destinados os resíduos, isto, visando um maior controle. 
Por fim, compreende-se que investir na aquisição de novas tecnologias visando à reutilização e à reciclagem desses materiais oriundos da construção civil, por meio de um processo de gestão adequada, atreladas a implantação de programas de minimização e redução de perdas, é fundamental para a empresa que busca se posicionar no mercado e se tornar referência em boas práticas ambientais.

\section{Metodologia}

No que tange aos procedimentos metodológicos adotados no estudo em questão, optouse pela elaboração de uma pesquisa sistemática. A revisão sistemática faz uso de métodos para identificar, selecionar e avaliar criticamente pesquisas relevantes, a fim de coletar e analisar dados de estudos incluídos na revisão (SAUR-AMARAL, 2010).

As revisões sistemáticas representam estudos secundários, que têm nos estudos primários sua fonte de dados (GIL, 2016). No presente trabalho, foram reunidos estudos relevantes sobre a temática enfocada. As principais publicações utilizadas foram: John (2010); Cunha (2011); Pinto; Lima Júnior (2014); Mariano (2012) e Tozzi (2006).

Quanto à abordagem, esta pesquisa é qualitativa, uma vez que esta não se preocupou com representatividades numéricas ou estatísticas (GIL, 2016), mas, sim, com o aprofundamento da compreensão acerca do fenômeno em análise, qual seja: gerenciamento de resíduos sólidos e a aplicação da logística reversa no segmento da construção civil.

Quanto aos fins, o presente estudo é descritivo-exploratório. A pesquisa descritiva requer do investigador uma sucessão de informações sobre o que busca pesquisar; esse tipo de estudo tem o intuito de descrever os fatos e fenômenos de determinada realidade (TRIVIÑOS, 2014).

Já a pesquisa exploratória tem como objetivo propiciar maior familiaridade do pesquisador para com o problema, com vistas a torná-lo mais claro ou a formular hipóteses. A maior parte dessas pesquisas abrange: levantamento bibliográfico; entrevistas com pessoas que tiveram experiências práticas com o problema pesquisado; e análise de exemplos que estimulem o entendimento sobre o tema pesquisado (GIL, 2016). 


\section{Considerações Finais}

Verificou-se, com base na revisão sistemática realizada ao longo do estudo, que os agentes geradores de resíduos são responsáveis pela gestão destes, devendo os mesmos certificar-se de que estes materiais sejam quantificados, armazenados, transportados e encaminhados para locais onde possam ser aproveitados ou depositados corretamente.

Observou-se que o setor industrial da construção civil enquadra-se dentre as cadeias produtivas, nas quais as atividades econômicas possuem impactos diretos sobre o meio ambiente, seja no uso e ocupação do solo, demanda sobre mananciais de água, extração de recursos naturais como matéria prima, como também na geração de resíduos.

Tendo em vista a importância econômica e social da indústria da construção civil no país, e a carência por tecnologias de gestão em que se encontra o setor atualmente, ações que promovam melhorias gerenciais terão grande importância para o alcance do desenvolvimento sustentável.

Constata-se, em consonância com os estudos de Cunha (2011), John (2010), Pinto (2015), Tozzi (2006), Lima (2012), Mariano (2012) e Pessoa (2008), que a implantação do gerenciamento de resíduos sólidos e a aplicação da logística reversa no segmento da construção civil podem promover uma redução no consumo de recursos naturais não renováveis; redução de áreas necessárias para aterro pela minimização de volume de resíduos pela reciclagem; redução do consumo de energia durante o processo de produção; redução da poluição; podendo gerar, também, uma economia aos cofres públicos e às empresas, pois o transporte e o descarte dos RCC geram muitas despesas.

Para que haja efetividade na aplicação da logística reversa no segmento da construção civil, faz-se premente que haja planejamento detalhado e gerenciamento dos fluxos direto e reverso, além disso, é necessário que a gestão, o controle e o planejamento das normas técnicas sejam compartilhados com os fornecedores de materiais e produtos, devido a diversidade elevada de produtos empregados na construção civil. Estas medidas influenciarão diretamente em uma melhor e mais eficiente triagem, segregação, coleta e disposição final desses materiais.

Como sugestão para outros trabalhos recomendam-se temas voltados à análise do ciclo de vida de materiais de construção, alternativas para reciclagem de resíduos de gesso e tintas, tratamento de resíduos de demolição, viabilidade de usinas de reciclagem de entulho, etc.

A perspectiva de ampliação das ações voltadas para a gestão dos resíduos provenientes da construção civil, tendo em vista a melhoria do desempenho ambiental, é bastante promissora, visto que quando o empresário toma conhecimento do custo do desperdício de recursos, a 
tendência é de que passe a tratar a gestão ambiental como uma oportunidade de melhorar o resultado financeiro de suas obras, reduzindo o consumo de recursos com uma menor geração de resíduos.

\section{Referências}

ALT, Paulo R.; MARTINS, Petrônio G. Administração de Materiais e Recursos Patrimoniais. 3. ed. São Paulo: Saraiva, 2011.

ALESSIO, Rosemeri. Responsabilidade social das empresas no Brasil: reprodução de postura ou novos rumos? Porto Alegre: EDIPUCRS, 2013.

ASSOCIAÇÃO BRASILEIRA DE EMPRESAS DE LIMPEZA PÚBLICA E RESÍDUOS ESPECIAIS (ABRELPE). Panorama dos resíduos sólidos no Brasil - 2015. Disponível em: http://www.abrelpe.org.br/Panorama/panorama2015.pdf. Acesso em: 05 de nov. 2017.

BÉRRIOS, Manuel. Consumismo e Geração de Resíduos Sólidos. GEOUSP. São Paulo: $n^{\circ}$ 6, p.17-28, 2009.

BRASIL. Constituição (1988). Constituição da República Federativa do Brasil. Brasília, DF: Senado Federal: Centro Gráfico, 1988. 292 p.

CALDERONI, S. Os bilhões perdidos no lixo. 6. ed. São Paulo: Humanitas, 2015. 346 p.

CAVALCANTI, Clovis. Sustentabilidade da economia: paradigmas alternativos da realização econômica. In: CAVALCANTI, Clovis (org). Desenvolvimento e natureza: estudo para uma sociedade sustentável. São Paulo: Cortez; Recife, PE: Fundação Joaquim Nabuco. 1998.

Clovis. Política de governo para o desenvolvimento sustentável: uma introdução ao tema e a esta obra coletiva. In: CAVALCANTI, Clóvis (org.). Meio ambiente desenvolvimento sustentável e políticas públicas. São Paulo: Cortez: Recife: Fundação Joaquim Nabuco, 2001.

CONSELHO NACIONAL DO MEIO AMBIENTE - CONAMA. Resolução n. 307, de 5 de julho de 2002. Publicada no DOU n. 136, de 17 de julho de 2002.

de fevereiro de 1986.

CONAMA. Resolução n. 001, de 23 de janeiro de 1986. Publicada no DOU de 17

CUNHA, V. Gerenciamento da coleta de resíduos sólidos urbanos: estruturação e aplicação de modelo não-linear de programação por metas. Dissertação (M. S.). Escola Superior de Agricultura Luiz de Queiroz. Universidade de São Paulo. Piracicaba, 2011.

CHAVES, Gisele de Lorena D; MARTINS, Ricardo Silveira. Diagnóstico da Logística Reversa na Cadeia de Suprimentos de Alimentos Processados no Oeste Paranaense In: VIII Simpósio de Administração da Produção, Logística e Operações Internacionais (SIMPOI), ago. 2005, São Paulo. Anais... São Paulo: FGV, 2005,

DAFT, Richard L. Administração. Tradução: Dalton Conde de. Alencar. 8. ed. Rio de Janeiro: LTC, 2015. 
D’AMBRÓSIO, D. A responsabilidade que dá retorno social. Jornal Gazeta Mercantil, publicado em 10 de novembro de 2010.

FERREIRA, Luiz Henrique (org.). Sustentabilidade nas Obras e nos Projetos: Questões Práticas para Profissionais e Empresas. São Paulo: PINI, 2012.

FERREIRA, Aurélio Buarque de Holanda. Dicionário da língua portuguesa. 12. ed. Curitiba: Positivo, 2017.

GOUVEIA, Nelson. Resíduos sólidos urbanos: impactos socioambientais e perspectiva de manejo sustentável com inclusão social. Ciência \& Saúde Coletiva, 17(6):1503-1510, 2012.

JOHN, V. M. Reciclagem de resíduos na construção civil: contribuição à metodologia de pesquisa e desenvolvimento. Tese (Título de Livre Docência). Departamento de Engenharia de Construção Civil. Escola Politécnica da Universidade de São Paulo. São Paulo. 2010.

LEITE, P. R. Logística Reversa: meio ambiente e competitividade. 9. ed. São Paulo: Pearson. 2016.

LIMA, Rosimeire Suzuki; LIMA Ruy Reynaldo Rosa. Guia para Elaboração de Projeto de Gerenciamento de Resíduos da Construção Civil. Série de Publicações Temáticas do CREA-PR, Paraná, 2012.

MARIANO, Leila Seleme. Gerenciamento de Resíduos da Construção Civil com Reaproveitamento Estrutural: Estudo de Caso de uma Obra com $4.000 \mathrm{~m}^{2}$. Universidade Federal do Paraná. 2012.

MANZINI, E; VEZZOLI, C. O desenvolvimento de produtos sustentáveis: os requisitos ambientais dos produtos industriais. São Paulo: Editora da USP, 2015.

MUÑOZ, Susana Inés Segura. Impacto Ambiental na Área do Aterro Sanitário e Incinerador de Resíduos Sólidos de Ribeirão Preto, SP: Avaliação dos níveis de metais pesados. 2012.

OLIVEIRA, M.J.C. Empresas e responsabilidade Social. In: III Congresso Brasileiro de Ciências da Comunicação. Bahia, 2012.

PESSOA, Elizabeth Vieira. Gestão de Resíduos de Construção Civil: Alternativas Adotadas Para Segregação, Coleta e Destinação de Resíduos de Construção de Edificações com Base em um Estudo de Casos. Dissertação apresentada ao Curso de Mestrado em Engenharia Ambiental Urbana da Escola Politécnica da UFBA. 2008.

PINTO, T.P. Gestão ambiental dos resíduos da construção civil: a experiência do SINDUSCONSP. São Paulo: SindusCon, 2015. 45p.

PINTO, Janaina Antonino; LIMA JÚNIOR, Orlando Fontes. Aplicação do Conceito de rede Logística Reversa na Construção Civil. XVIII ANPET - A Associação Nacional de Pesquisa e Ensino em Transportes. Florianópolis, 2014.

ROCHA, J.C.; JOHN, V.M. Utilização de resíduos na construção civil. Porto Alegre: Coletânea Habitare, Volume 7, 2013. 
SAUR-AMARAL, I. Revisão sistemática da literatura. BUBOK. Lisboa, 2010.

STACHERA JÚNIOR, T. Avaliação de emissões de CO2 na construção civil: um estudo de caso da habitação de interesse social no Paraná. In: XXVIII Encontro Nacional de Engenharia de Produção. Rio de Janeiro, RJ, Brasil, 13 a 16 de outubro de 2008.

SCHENINI, Pedro Carlos; BAGNATI, Antonio; CARDOSO, André. Gestão de Resíduos Sólidos na Construção Civil. In: COBRAC - Congresso Brasileiro de Cadastro Técnico Multifinalitário. Florianópolis, UFSC, 2004.

TACHIZAWA, Takeshy; GARRETT, Alexandre. Indicador de desenvolvimento humano organizacional: novas dimensões da cultura corporativa. São Paulo: Cultura, 2010.

TEIXEIRA, E.N.; BIDONE, F.R.A. Conceitos básicos - Metodologia e técnicas de minimização, reciclagem e reutilização de resíduos sólidos urbanos. Rio de Janeiro: ABES (Associação de engenharia Sanitária e Ambiental). 2009.

TORGAL, F. P.; JALALI, S. Construção sustentável: o caso dos materiais de construção. In: Congresso Nacional “Construção”, 3, 2007, Coimbra. Anais... Coimbra. 2007.

TOZZI, Rafael Fernando. Estudo da Influência do Gerenciamento na Geração dos Resíduos da Construção Civil (RCC) - Estudo de Caso de Duas Obras em Curitiba - PR. Dissertação apresentada como requisito parcial à obtenção do grau de Mestre em Engenharia de Recursos Hídricos e Ambiental, Curitiba: 2006.

TRIVIÑOS, A. N. S. Introdução à pesquisa em ciências sociais: a pesquisa qualitativa em educação. 11. ed. São Paulo: Atlas, 2014.

VEIGA, José Eli da. Desenvolvimento sustentável: o desafio do século XXI. Rio de Janeiro: Garamond, 2015.

XAVIER, L. L.; ROCHA, J. C. Diagnóstico do resíduo da construção civil - Início do caminho para o uso potencial do entulho. In: IV Seminário Desenvolvimento Sustentável e a Reciclagem na construção civil - materiais reciclados e suas aplicações. CT206 - IBRACON. São Paulo - SP. 2001.

\section{Como citar este artigo (Formato ABNT):}

MATOS, João Paulo Cavalcante; ALENCAR, Tharsis Cidália de Sá Barreto Diaz de. Gerenciamento de Resíduos Sólidos e a Aplicação da Logística Reversa no Segmento da Construção Civil. Id on Line Rev.Mult. Psic., 2019, vol.13, n.43, p. 784-807. ISSN: 1981-1179.

Recebido: 24/11/2018;

Aceito: 26/11/2018 